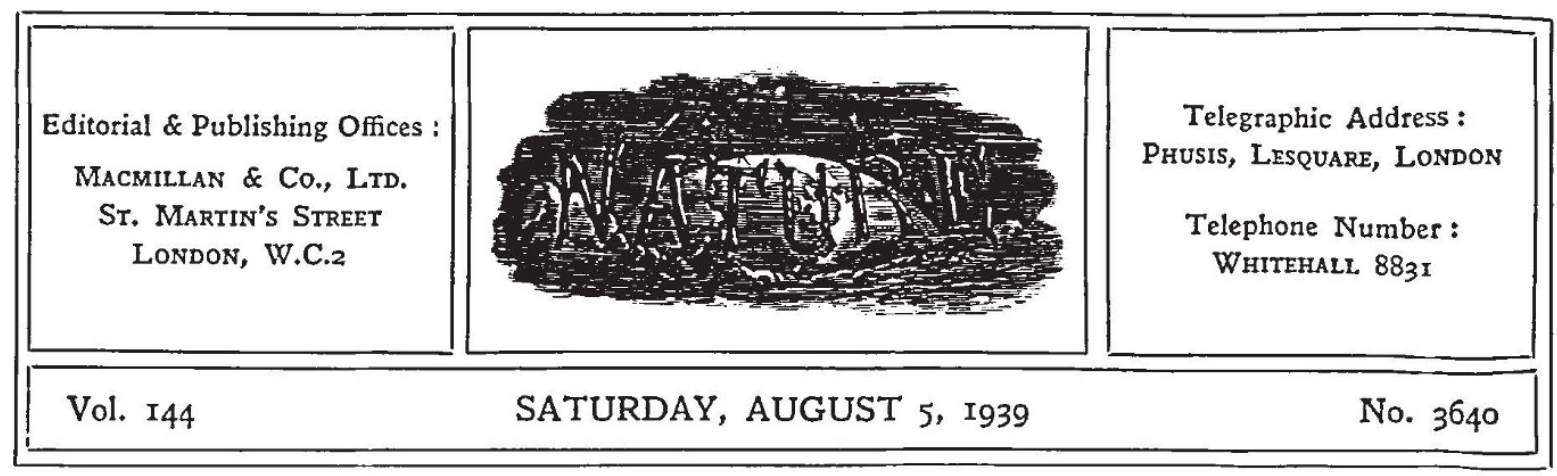

\title{
DEMOCRACY AND LEADERSHIP
}

$\mathrm{I}^{\mathrm{N}}$ a volume entitled "Recovery: the Second Effort", Sir Arthur Salter outlined a scientific programme of recovery conspicuous for its vision and sense of values. He has now produced an equally comprehensive review* of the international situation to-day, which outlines an equally scientific programme for retrieving security, no longer in the field of economics but in that of power politics. Beyond this, however, Sir Arthur has given us not only a frank and realistic picture of the grave dangers which confront democracy and all that it stands for to-day, not merely a challenge, but also a vision of hope. Through all the dangers which now confront democracy, he sees its innate strength. Its weakness can still be repaired in time if we but bring to the service of its virtues bred and nursed to the pursuit of peace, the sterner virtues of fortitude, energy, the will to act together, the free acceptance of discipline and sacrifice. Faults of organization and leadership can be made good if recognized, and the book is to be welcomed even if only for this reminder that with courage and vision, the recognition of danger and not the refusal to see it, we can yet eliminate the sources of weaknesses in the free democracies.

Sir Arthur opens with a trenchant analysis of the chief material and political factors involved in the present position, and sets in clear relief the dangers confronting the democracies and the factors likely to precipitate conflict or avert it. Scientific workers, no less than the general reader, should welcome this sane and concise review of the situation.

The second part of the book consists of a brief review of the events and ideas which have been responsible for the failure to achieve collective

* Security : Can we Retrieve It ? By Sir Arthur Salter. Pp. xv +390 (London: Jacmillan and Co., Ltd., 1939.) 88. 6d. net. security in the last two decades through the League of Nations. In this review, emphasis is laid in the transformation of the character of the League from the start, through the abstention of the United States and later defections with their consequences.

Sir Arthur Salter urges the undesirability as well as uselessness of attempting amendment of the League Covenant at present. The main task in respect of the League is to keep its organization active and efficient by developing the useful work which it can continue on social, economic and financial and labour questions. This pertinent reminder of the valuable work which is still being done in a number of technical and scientific fields should not be lost on scientific workers. We must have regard both to the practical and to the ideal. The ultimate goal must be either the restoration of the League, or the construction of some other form of collective system, including the revision of treaties by collective negotiation. Until we achieve this, peace must be at best precarious.

'The third part of the book, entitled "National Strength", which is the longest of the five, deals with the various factors in the domestic situation. It contains most of the detailed criticism which Sir Arthur allows himself and reveals to the full the author's rich administrative experience and capacity. It is this section, with its highly stimulating and suggestive remarks regarding leadership, that scientific workers should find of special interest. In the fourth part, Sir Arthur outlines his views on present policy to lay the foundation of a new peace. He sets forth proposals for the basis of the discussion of a general settlement with Germany when conditions make the reasonable discussion of such a settlement practicable as an example of what might be possible with the other Axis powers also, while in 
the fifth part of the book he discusses the strength and weaknesses of the democracies and totalitarian systems, and summarizes the policy and action required in defence of democracies.

The policy outlined by Sir Arthur has every claim to be described as a scientific policy and as such merits the attention and support of all scientific workers. He reiterates, for example, the case for a Ministry of Supply as a first step in the reorganization needed to enable industry to meet the vast demands of the war services, and the arguments in support of the case with which he has long been associated are marshalled with force and lucidity. Here again he is on ground that is already common with many scientific workers, and this chapter on industrial mobilization deserves their close attention.

Beyond such particular questions, this part of the book raises the fundamental questions of leadership in a democracy. By what is implied, as much as by what is said, Sir Arthur Salter indicates the limitations and defects of leadership in Great Britain in the last decade or more, the lack of vision, the failure not merely to foresee dangers but even to recognize their existence. Once again he directs attention to the dangers of professional departmentalism and to the obstacles it opposes to vigorous and effective action in any new field. Not only in regard to the storage of food and air raid precautions, but also in such matters as the location of industry, Sir Arthur Salter is seriously disturbed at evidence of failure on the part of the Government to realize what is involved, and the charge of executive incompetence which he presses home is the more impressive through its sober restraint.

Inevitably such criticism raises the whole ques. tion of the selection of executive ministers in a democracy in times of such stress. Far closer co-operation between the Government service and the public is required if the economic adaptation necessitated in modern warfare is to be achieved and quick and vigorous action facilitated both by the Government and by industry.

To this end seceral specific proposals are made. The personnel of the Civil Service should at once be reinforced; at the top with the leading men in science and industry, and throughout its ranks with young men of energy and constructive ability, some of whom would be specialists and others, while without specialized experience, should have a trained and adaptable intelligence. In addition to full transfer, Sir Arthur suggests that competent men of energy and constructive ability and useful specialized knowledge in finance and other business houses could be associated at once with appropriate departments on a part-time basis. Stress is also laid on the opportunity for private initiative and, in particular, it is suggested that scientific men, without waiting to be consulted on particular questions, should take the initiative themselves by reviewing in turn the obvious problems in which scientific knowledge is not as yet fully utilized.

In regard to the executive, Sir Arthur suggests a small inner Cabinet of Ministers, relieved of departmental duties, of suitable personal qualities to conceive and elaborate a general policy and furnished with an adequate and appropriate organization. Stressing the importance of national unity, he would broaden the basis of the National Government and suggests the appointment by Parliament of a Committee of Foreign Policy and Defence, consisting of twenty or thirty of the most trusted members of all important parties or groups.

This criticism, which rarely fails to be constructive, is essentially a most stimulating and suggestive essay on leadership in democracy in which, for all its failings, Sir Arthur is a convinced believer. Inadequate preparations are not due to inherent defects in our parliamentary system. Some of the conditions which militate against the selection of requisite administrators and executives of ability are clearly indicated by Sir Arthur, but his essay should at least stimulate much fundamental and constructive thinking about the selection and training of leaders for the highest positions both in industry and in the State. Scientific workers, no less than other members of the community, may well be grateful that Sir Arthur has lent the weight of his unrivalled experience as an administrator to the exposition of the dangers and possibilities of the present situation. The realization of the menace, no less than the message of hope which breathes through the pages of this book, may well assist in overcoming the obstacles to the more centralized direction and coherent planning of all our effort and stimulate the acceptance of the essential discipline and sacrifice. Nor should this constructive and inspiring book fail also to stimulate fundamental thought on the evolution of modifications in our democratic institutions, which will enable them to meet the strain more effectively and to throw up the leaders required, while preserving unimpaired the great traditions which are theirs and theirs alone. 